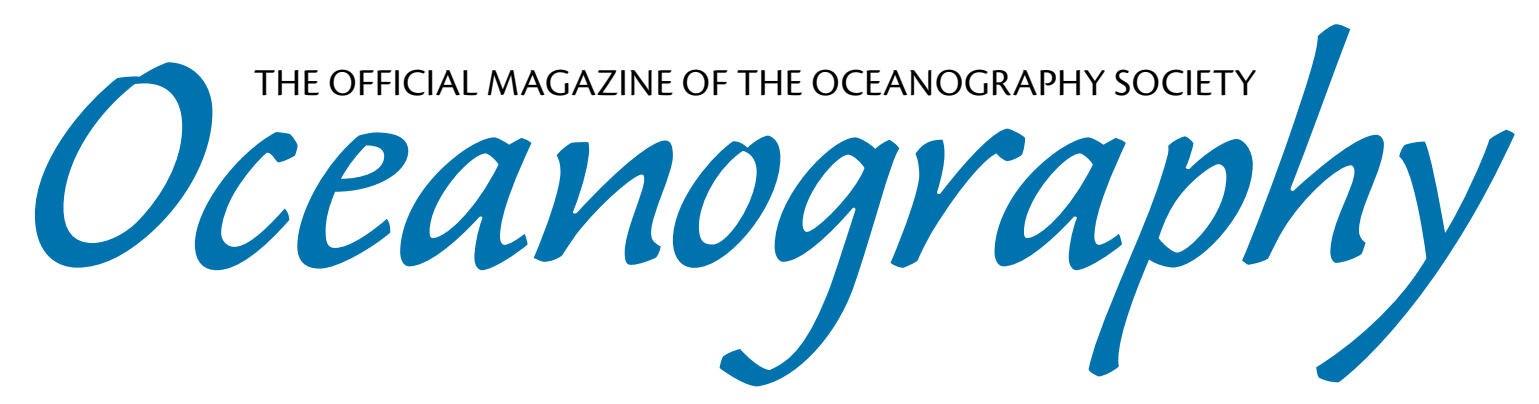

CITATION

Roman, M. 2012. From the President: The 2012 Ocean Sciences Meeting. Oceanography 25(2):6, http://dx.doi.org/10.5670/oceanog.2012.57.

DOI

http://dx.doi.org/10.5670/oceanog.2012.57

COPYRIGHT

This article has been published in Oceanography, Volume 25, Number 2, a quarterly journal of The Oceanography Society. Copyright 2012 by The Oceanography Society. All rights reserved.

USAGE

Permission is granted to copy this article for use in teaching and research. Republication, systematic reproduction, or collective redistribution of any portion of this article by photocopy machine, reposting, or other means is permitted only with the approval of The Oceanography Society. Send all correspondence to: info@tos.org or The Oceanography Society, PO Box 1931, Rockville, MD 20849-1931, USA. 


\section{The 2012 Ocean Sciences Meeting}

TOS was the lead society in organizing the February 20-24, 2012, Ocean Sciences Meeting held in Salt Lake City, Utah. Along with partner societies, the American Geophysical Union (AGU) and the Association for the Sciences of Limnology and Oceanography (ASLO), the planning effort took over two years under the able leadership of the meeting co-chairs Mel Briscoe (TOS), Eric Itsweire (AGU), and Mary Scranton (ASLO). Great credit is also due to the meeting organizing committee, which developed the scientific program and meeting schedule. Helen Schneider Lemay and her staff at SG Meeting and Management Services did their usual excellent job of managing logistics, including registration, exhibits, and catering. Critical in all these meeting preparations and oversight were the efforts of Jenny Ramarui, Executive Director of The Oceanography Society.

Meeting registration totaled 3,897 individuals, representing 55 countries. There were 3,536 abstracts accepted for 1,265 oral presentations and 2,271 posters. These presentations were grouped into 108 oral science sessions and 146 poster sessions. There were 54 exhibitors: 33 commercial, four government agencies, and 17 nonprofits.
Surveys from the meeting participants showed that, in general, people liked the meeting format and venue. We had many positive comments about the Wednesday morning plenary session, which had great talks and provided a sense of community for the meeting. Participants liked having posters up all week, the large poster area, and the grab-and-go snacks that provided energy for poster presenters and their audiences. Salt Lake and its Convention Center were great hosts, providing easy access, good service, and friendly people.

The meeting report and recommendations have been handed off to the 2014 Ocean Sciences Meeting co-chairs: Jonathan Sharp (ASLO), Mel Briscoe (TOS), and Eric Itsweire (AGU), who have already started to plan for the 2014 meeting in Hawaii, where we look forward to another great Ocean Sciences Meeting!

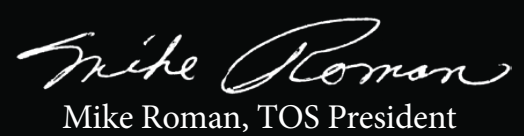

Mike Roman, TOS President

\section{AWARDS}

\section{THE 2012 OCEAN SCIENCES MEETING STUDENT AWARDS}

The Oceanography Society would like to congratulate student participants whose presentations were recognized for displaying notable scientific innovation and significant insight through clear and concise presentation during the 2012 Ocean Sciences Meeting.

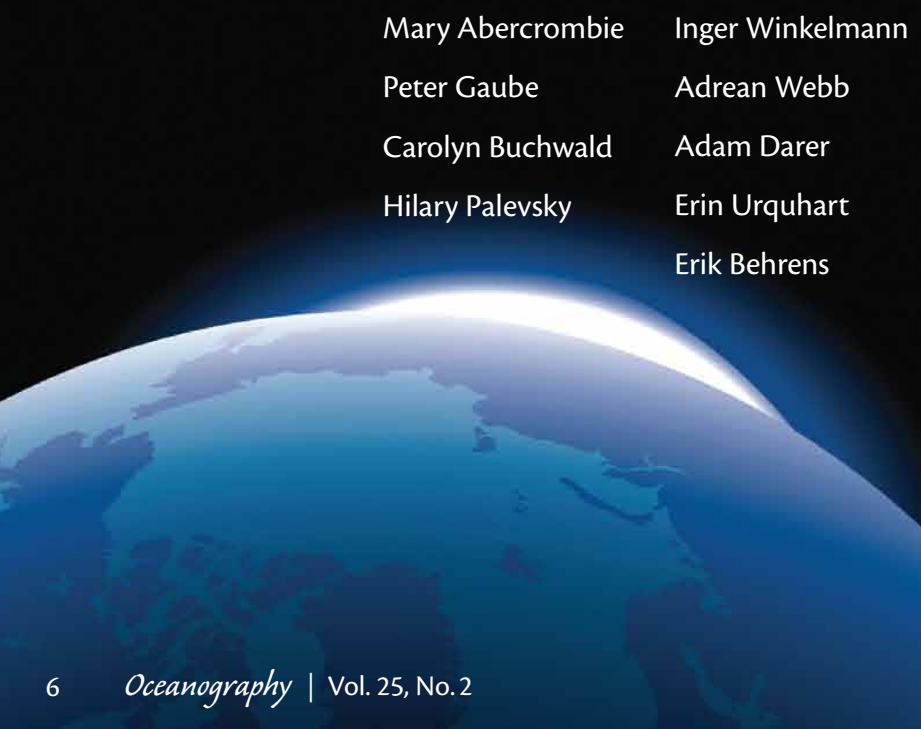

Heidi Burdett

Matthew Long

Miriam Goldstein

Jeanna Hudson

Sarah Moffitt

Andrew Madison

Yizhen Li

Rebecca Jackson

Nobuhiro Suzuki
Sylvia Rodriguez-Abudo

Julien Dekaezemacker

Núria Casacuberta

Dimitry Smirnov

Samantha Stevenson

Darren Dunlap

Katlin Bowman

Bethanie Edwards

Noel Pelland

Elizabeth Harvey

Chelsea Spier
Laura Dover-Good

Zhaoru Zhang

Steven van Heuven

Tonya Kane

Jamie Becker

Matthew Archer

Binbin Wang

Lael Vetter

Elizabeth Tobin

Sara Bender

Santiago Herrera 